Bayero Journal of Pure and Applied Sciences, 10(1): 428 - 433

ISSN 2006 - 6996

\title{
OPTIMIZATION OF PROTOCOL FOR MULTIPLE SHOOTS REGENERATION FROM APICAL MERISTEM OF EMBRYONIC AXES IN COWPEA (Vigna unguiculata L. Walp)
}

\author{
Sani $^{1^{*}}$, L. A., Usman ${ }^{2}$, I. S., Ishiyaku ${ }^{2}$, M.F. and S. M., Bugaje ${ }^{2}$ \\ 1. Department of Plant Biology, Bayero University Kano, Nigeria \\ 2. Department of Plant Science, Ahmadu Bello University, Zaria, Nigeria. \\ *Corresponding author: email: sanimalk@yahoo.co.uk
}

\begin{abstract}
In this work, we report a new approach for regeneration of multiple shoots from the apical meristem of embryonic axes in four elite cowpea varieties. The hypocotyl segments, primary and primordial leaves were removed and embryonic axes were placed in culture bottles containing Murashige and Skoog basal + B5 vitamins (MSB5) fortified with $22.2 \mu \mathrm{M}, 26.6 \mu \mathrm{M}$ or $31.0 \mu \mathrm{M} \mathrm{N}^{6}$-benzylaminopurine (BAP) to induce multiple shoots. Elongated shoots were obtained on regeneration media consisting of MSB5 supplemented with low concentration $(2.22 \mu \mathrm{M})$ of $B A P$. Hormone free media promoted direct regeneration of single shoots from the apical meristems of embryonic axes, while the presence of BAP promoted callus induction and indirect regeneration of multiple shoots. Of the BAP concentrations evaluated, $22.2 \mu \mathrm{M}$ produced the highest regeneration frequencies $(20.3 \%, 28.5 \%$ and $23.8 \%)$ and mean shoots numbers (4.3, 4.0 and 4.1) in SAMPEA 7, SAMPEA 10 and SAMPEA 12 respectively. While, in

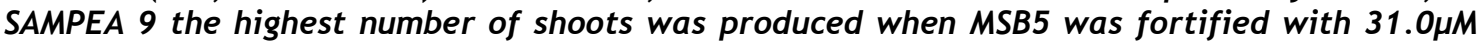
$B A P$. Regenerated plantlets were rooted on hormone free media and acclimatized in the greenhouse. Morphologically normal and fertile progenies were obtained from the greenhouseestablished generated plants. This protocol could be useful in the genetic engineering of cowpea thereby generating useful transgenic lines for future breeding programmes.
\end{abstract}

Keywords: Cowpea, Embryonic axes, Regeneration, Multiple shoots, $N^{6}$-benzylaminopurine

\section{INTRODUCTION}

Cowpea (Vigna unguiculata L. Walp) is a major food crop in sub-Saharan Africa and many countries in Asia and America. It is an important source of dietary protein with both its dry grain and vegetative parts containing $23-32 \%$ protein and other important food components such as carbohydrate, lipid, fiber, minerals and vitamins (Nielson et al., 1993). About 7.56 million metric tons of cowpea is produced annually over an estimated area of 12.76 million hectares with over $70 \%$ of the dry grain production coming from sub-Saharan Africa (www.iita.org/cms/detail/cowpea_project_det ails). Production of cowpea is severely limited by biotic constraints, among which, the most critical are attack by insect pests and diseases. These reduce the overall grain yield under farmers' management in sub-Saharan to an average of $0.495 \mathrm{t} / \mathrm{ha}$ which per below the crop's potential estimated at3.0t/ha (FAO, 2012).

Genotypes with inherent resistance to biotic stresses are needed to increase the productivity of cowpea and make its production more profitable. Attempts to introduce genes for resistance for pests and diseases by interspecific hybridization with wild relatives were not successful because of the compatibility barrier (Singh et al., 2000). Transgenic technology is one veritable alternative that my help breeders overcome these challenges, especially when applied alongside with conventional breeding.

For successful genetic improvement of cowpea, regeneration system that will provide totipotent cells which foster the development of complete plants is required. Although in vitro regeneration techniques were reported in cowpea, many of the factors that regulate plant regeneration are not fully understood. Compared to other grain legumes such as Soybean and Common bean (Atifet al., 2012), cowpea perform poorly under in vitro conditions. As starting materials, several explants that include mature and immature embryos, primary leaves, cotyledon, cotyledonary node, epicotyl, hypocotyl, thin cell layer, stem segment, shoot tip, plumular apices, shoot meristem and root tip were employed in regeneration of cowpea (for a review see Saniet al., 2015). Of all the explants, Cotyledonary node is the most widely used explant for multiple shoots regeneration and Agrobacterium mediated transformation (Popelkaet al., 2006; Raveendaret al., 2009;Bakshi and Sahoo, 2013). 
This system however, is tedious, requires elaborate treatment of the initial explant and several cultivation steps before regeneration is achieved. Cotyledonary node explant is not suitable explant for biolistic mediated transformation which is both simple and variety independent. Currently, biolistic - mediated transformation of cowpea using apical meristem of embryonic axes (Citadinet al., 2013; Cruz and Aragao, 2014) is based on single shoot regeneration. A regeneration system that obtains multiple shoots from the apical meristematic region of embryonic axes could increase the rate at which we obtain transgenic lines in cowpea. Earlier reports indicated that multiple shoots were obtained from embryonic axes of cowpea following removal of apical region to suppress apical dominance (Popelkaet al., 2006; Rajiet al., 2008). In this report, we describe a protocol for multiple shoots regeneration from the apical region of embryonic axes in cowpea. The system is simple and requires only two cultivation steps. Moreover, since shoots were regenerated from the intermediary callus formed during the induction phase, the system could be used in both Agrobacterium and biolistic-mediated genetic transformation of cowpea.

\section{MATERIALS AND METHODS}

To identify cowpea genotypes with superior regeneration potentials under in vitro condition, eight elite cowpea varieties (SAMPEA) developed by Institute for Agricultural Research (IAR), Ahmadu Bello University, Zaria, Nigeria were used in preliminary studies. These varieties include SAMPEA 7, SAMPEA 8, SAMPEA 9, SAMPEA 10, SAMPEA 11 , SAMPEA 12, SAMPEA 13 and SAMPEA 14. Fresh seeds of these varieties were collected from cowpea breeding unit and were surface-sterilized with $70 \%$ ethanol for 1 minute followed by immersion in $20 \%$ commercial bleach $(3.5 \% \mathrm{w} / \mathrm{v}$ sodium hypochlorite) for 20 minutes. The seeds were then rinsed three times in sterile distilled water and soaked for 18-20 hours. Embryonic axes were excised and cultivated on full strength, three-quarter (3/4) strength and half strength $(1 / 2)$ MS salts with B5 vitamins supplemented with $30 \%$ sucrose and $512 \mu \mathrm{M} / \mathrm{L}$ 2-(N-morpholino) ethanesulfonic acid (MES). Growth and development of the in vitro seedlings was monitored over a period of two weeks. Four genotypes which included SAMPES 7, SAMPEA 9, SAMPEA 10, and SAMPEA 12 were identified to have the best in vitro growth performance and were selected for the protocol development. Seeds of these genotypes were surface sterilized as described above and embryonic axes were excised. Apical meristems of the embryonic axes were exposed by removing both the primary and primordial leaves under stereomicroscope. Embryonic axes were sterilized for the second time in 5\% commercial bleach for 10 minutes and rinsed three times in sterile distilled water. Embryonic axes were then blotted-dry on sterile filter paper and hypocotyl segments were removed before cultured on shoot induction media.

The shoots induction media consisted of MS (Murashige and Skoog, 1962) basal salts plus B5 vitamins (Gamborget al., 1968) (MSB5) supplemented with $512 \mu \mathrm{M} / \mathrm{L}$ 2-( $N$-morpholino) -ethanesulfonic acid (MES) (Sigma, USA), $1 \mathrm{mM} / \mathrm{L}$ L-glutamine, $30 \mathrm{~g} / \mathrm{L}$ sucrose and fortified with $22.2 \mu \mathrm{M}, 26.6 \mu \mathrm{M}$ or $31.0 \mu \mathrm{M} \mathrm{N} N^{6}$ benzylaminopurine (BAP) (Sigma, USA) solidified with $8 \mathrm{~g} / \mathrm{L}$ agar (Sigma, USA). The $\mathrm{pH}$ of the medium was adjusted to 5.8 before autoclaving for 15 minutes at $121^{\circ} \mathrm{C}$. In each culture bottle, eight embryonic axes were cultured in an upright position and 5 five culture bottles were used for each treatment in a Completely Randomized Design (CRD). Cultures were kept for 7 days under 16 hour photoperiod. After 7 days on shoots induction media, explants were transferred to regeneration medium consisting of MSB5 supplemented with lower concentration of BAP $(2.22 \mu \mathrm{M})$. Explants were maintained in regeneration media for six weeks with subculture on fresh medium at 2 week intervals. After the first two weeks on regeneration media, data on the days to regeneration (time at which the emergence of shoot buds was observed under the binocular microscope), percentage regeneration (number of embryos regenerating shoots expressed as percentage of total embryonic axes cultured) were taken at regular intervals. Number of elongated shoots per explants were taken after six weeks on regeneration media and for shoot length, elongated shoots were removed from the regeneration media and length of plantlets at least $1.0 \mathrm{~cm}$ long were taken and the average was recorded. Plantlets were separated and culture on hormone-free MSB5 for root induction. Plantlets with welldeveloped roots were washed with water to remove the agar and transplanted to river sand: manure (ratio sand 1: 3 manure) in plastic cups covered with transparent polyethylene bags to maintain high humidity. Plants were grown at $27-29^{\circ} \mathrm{C}$ in the greenhouse for 2 weeks before the polyethylene bags were removed. Plants were then transferred to bigger plastic pots and allowed to grow to maturity. Data collected was subjected to analysis of variance (ANOVA) and means were separated using Duncan's multiple-range test (DMRT). 
In case of percentage regeneration, data was transformed using square root $\sigma(\mathrm{y}+0.5)$ before

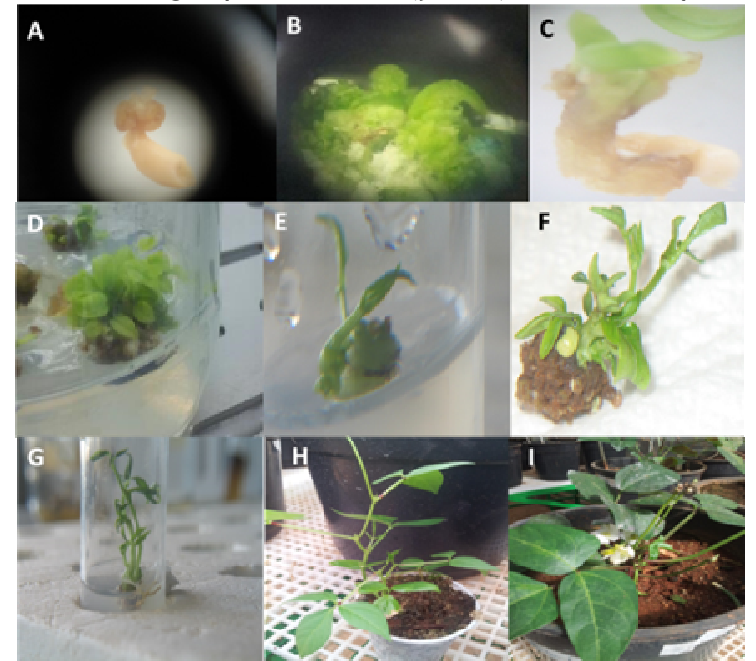

analysis and were converted back to percentages for presentation.

Figure 1: Stages in multiple shoots regeneration by organogenesis from apical meristem of embryonic axes in cowpea (Vigna unguiculata L. Walp). Explants were cultured on MSB5supplemented with $30 \mathrm{~g} / \mathrm{L}$ sucrose and $100 \mathrm{mg} / \mathrm{L}$ MES. (A) Callus development (B) Shoot buds development (C) Few shoot buds began elongation, (D) Shoot buds developed into leafy clusters, (E) Shoots began elongation, (F) Fully elongated shoots, (G) Shoots on rooting media, (H) Acclimatize seedling (I) Matured and fertile plant.

\section{RESULTS AND DISCUSSION}

When embryonic axes were cultured on hormone free medium, explants responded by showing green colour and subsequent development of a single shoots from the apical meristems. On the other hand, in the presence of BAP embryos responded by turning green with subsequent formation of greenish callus at the merismatic regions (Figure 1a). Large number of shoot buds developed from the apical merismatic regions after two weeks on regeneration media. When viewed under microscope, these buds were seen to initiate from the intermediary callus (Figure 1C). Despite the large number of buds initiated, only a few developed past the bud stage with most of the buds remaining as bushy structure (figure 1D).Successful regeneration of cowpea by direct or de novoorganogenesis has earlier been reported from various explants (for a review see Saniet al., 2015). Our choice of embryonic axes as the preferred explant is driven by the fact that, it constitutes the most suitable explant for transformation of cowpea using the biolistic method and if multiple shoots could be obtained especially via de novo organogenesis, it could also be used in Agrobacterium mediated transformation. Moreover, multiple shoots regeneration following gene delivery could also be a useful strategy to increase transformation frequency, thereby increasing the chance of getting transgenic plants with stable transformation.

Regeneration frequency (expressed as percentage of total number of embryonic axes cultured) was significantly influenced by the concentrations of BAP. The highest regeneration frequency was obtained in SAMPEA 10(28.5\%), SAMPEA $12(23.8 \%)$ and SAMPEA 7 (20.9\%)in the presence of $22.2 \mu \mathrm{M}$ BAP. In all these genotypes regeneration frequencies decreased when the concentration of BAP were increased (Table 1.0). In SAMPEA 9, however, treatment with BAP had no significant influence on the regeneration frequency (Table 1).Shoots regeneration in cowpea was enhanced by preconditioning cotyledons and cotyledonary nodes in high concentrations of BAP (Amitha and Reddy, 1996; Braret al.,1999; Raveendaret al., 2009; Mammanet al., 2013), in TDZ (Bakshi et al., 2012) and in NAA (Aasim, 2010). Multiple shoots were also regenerated from embryonic axes of cowpea in the presence of BAP following decapitation to eliminate apical dominance (Popelkaet al., 2006; Rajiet al., 2008).Generally, we observed that explant cultured on hormone free medium produced lower percentage regeneration and this observation become clear when comparison of regeneration response in explants culture on hormone free media and those cultured on media containing BAP was made irrespective of the hormone concentration. 
These findings were also consistent with reports in cowpea (Raveendar et al., 2009; Mamman et al., 2013) and in other recalcitrant species (Gurel et al., 2011;Choudharyet al., 2009).In previous reports, successful regeneration of multiple shoots in cowpea was achieved only in explants with no defined apical dominance. In this work, however, multiples shoots were regenerated from apical meristem of embryonic axes demonstrating efficacy of BAP in suppressing apical dominance and induction of multiple shoots syndrome in cowpea. Earlier histological studies on meristem formation in cotyledonary explant in cowpea (Pellegrineschi, 1997, Muthukumar et al., 1996) demonstrated that, exposure to high concentration of BAP at induction phase stimulated the formation of clusters of actively dividing callus cells which developed into shoot meristems, thereby increased regeneration potential of the explant.

Variations in regeneration frequency were also recorded among the cowpea genotypes (Table 1).Across all the BAP concentrations, SAMPEA 10 produced the best regeneration frequency (15.4 - 28.5\%). This genotype was subsequently followed by SAMPEA $12 \quad(14.6-23.8 \%)$ and SAMPEA $7 \quad(14.6-20.9 \%)$ and the lowest regeneration frequency was recorded in SAMPEA 9 (12.4-13.4\%).Our results coincides with the findings of (Kucharska and Orlikowska, 2009;Bakshiet al., 2012) who reported increase in regeneration competence of different genotypes when explants were exposed to high concentration of cytokinin during the induction phase.

Number of shoots was also significantly $(P \leq$ 0.05 ) influenced by BAP concentrations. On hormone free media, embryonic axes gave rise to single elongated shoots in all the four cowpea genotypes (Table 1.0). However, multiple shoots were regenerated in the presence of BAP (Figure 1E). The number of shoots per embryonic axe increased by 2-7 folds when embryonic axes were cultured in media containing raised concentrations of BAP. In SAMPEA 7, SAMPEA 10 and SAMPEA 12, the highest mean shoot number was produced in the presence of $22.2 \mu \mathrm{M}$ BAP (Table 1). Further increase in BAP concentrations to $26.6 \mu \mathrm{M}$ or $31.0 \mu M$ significantly $(P \leq 0.05)$ decreased the number of shoots per embryonic axes. On the other hand, in SAMPEA 9, 31.0 $\mu$ M BAP produced the highest number of shoots per embryonic axes (3.0) and number of shoots decreased significantly $(P \leq 0.05)$ when BAP concentrations were reduced to $26.6 \mu \mathrm{M}$ or $22.2 \mu \mathrm{M}$ (Table 1 ). Popelka et al, (2006) andMao et al, (2006) reported regeneration of multiple shoots in cowpea in the presence of raised concentration of BAP. Working with Phellodendron amurense Rupr, (Azad et al., 2005) reported that, development of meristems and subsequent emergence of shoots from callus depends on the physiological state of the callus and the hormonal condition of the culture medium. Reeve,1948 and Gifford,1954 were the first to demonstrated that in dicot, development of meristem from callus follows the unica-corpus theory in which the initiating cells gathered into a central core (the corpus), which is enveloped by two or more layers or cells forming the tunica.

In conclusion, two distinct regeneration methods were developed in this study; 1 ) direct regeneration of single shoot from the apical meristem of embryonic axes cultured on hormone free medium and 2) the used of relatively high concentration of BAP to suppress apical dominance and induced multiple shoots formation. The present study demonstrated that, removal of primary leaves, primordial leaf and root apical dominance coupled with exposure to high concentration of BAP during the induction phase resulted in multiple shoots regeneration from the apical merismatic region of embryonic axes in cowpea. The protocol developed is simple and requires only two steps of cultivation. The simplicity and reproducibility of this system couple with regeneration of shoots from intermediary callus may be useful in both biolistic and Agrobacterium-mediated transformation of cowpea. 
Table 1: Effect of 7 days incubation on shoots induction media containing different concentrations $(22.2,26.631 .0 \mu \mathrm{M})$ of BAP on regeneration frequency and number of shoots per embryonic axes in cowpea

\begin{tabular}{ccccc}
\hline $\begin{array}{c}\text { Cowpea } \\
\text { Genotype }\end{array}$ & BAP $(\mu M)$ & $\begin{array}{c}\text { No of } \\
\text { explant }\end{array}$ & $\begin{array}{c}\text { Regeneration } \\
\text { Frequency }(\%)\end{array}$ & $\begin{array}{c}\text { Number of } \\
\text { Shoots }\end{array}$ \\
\hline SAMPEA 7 & 0 & 40 & $14.6^{\mathrm{d}}$ & $1.1^{\mathrm{g}}$ \\
& 22.2 & 40 & $20.9^{\mathrm{c}}$ & $4.3^{\mathrm{a}}$ \\
& 26.6 & 40 & $19.9^{\mathrm{c}}$ & $3.6^{\mathrm{b}}$ \\
SAMPEA 9 & 31.0 & 40 & $18.3^{\mathrm{c}}$ & $2.3^{\mathrm{e}}$ \\
& 0 & 40 & $13.4^{\mathrm{e}}$ & $1.3^{\mathrm{g}}$ \\
& 22.2 & 40 & $12.9^{\mathrm{e}}$ & $1.9^{\mathrm{f}}$ \\
SAMPEA 10 & 26.6 & 40 & $12.4^{\mathrm{e}}$ & $2.1^{\text {ef }}$ \\
& 31.0 & 40 & $13.0^{\mathrm{e}}$ & $3.0^{\mathrm{cd}}$ \\
& 0 & 40 & $20.3^{\mathrm{c}}$ & $1.1^{\mathrm{g}}$ \\
SAMPEA 12 & 22.2 & 40 & $28.5^{\mathrm{a}}$ & $4.0^{\mathrm{a}}$ \\
& 26.6 & 40 & $18.4^{\mathrm{c}}$ & $3.1^{\mathrm{c}}$ \\
& 31.0 & 40 & $15.4^{\mathrm{d}}$ & $2.8^{\mathrm{d}}$ \\
& 0 & 40 & $12.1^{\mathrm{e}}$ & $1.1^{\mathrm{g}}$ \\
& 22.2 & 40 & $23.8^{\mathrm{b}}$ & $4.1^{\mathrm{a}}$ \\
& 26.6 & 40 & $17.0^{\mathrm{d}}$ & $2.8^{\mathrm{d}}$ \\
& 31.0 & 40 & $14.6^{\mathrm{d}}$ & $1.9^{\mathrm{d}}$ \\
\hline
\end{tabular}

Acknowledgements:

The authors are grateful to Institute for Agricultural Research (IAR), Ahmadu Bello University, Zaria, Nigeria for financing this

\section{REFERENCES}

Aasim, M. (2010). In Vitro Shoot Regeneration of NAA-Pulse Treated Plumular Leaf Explants of Cowpea Not Sci Biol., 2 (2): 60-63.

Amitha, K., Reddy, T. P. (1996). Regeneration of plantlets from different explants and callus cultures of Cowpea (Vigna unguiculata L. ). Phytomorphology, 46(3):207-211.

Atif R. M., Patat-Ochatt, E. M., Svabova, L., Ondrej, V., Klenoticova, H., Jacas, L., Griga, M., and Ochatt, S. J. (2013). Gene Transfer in Legumes. In Luttge, U., Beychlag, W., Francis, D., Cushman, J. (eds.), Progress in Botany, 74, SpringerVerlag Berlin Heidelberg; 37-100. DOI: 10.1007/978-3-642-30967-0_2.

Azad, M. A., Yokota, S., Ishiguri, F., Yahara, S., Yoshizaw, N. (2005). Histological studies of shoot regeneration system in hypocotyl-derived callus of PhellodendronamurenseRupr. J For Res, 10:377-384, DOI 10.1007/s10310-0050148-9.

Bakshi, S., and Sahoo, L. (2013). How Relevant is Recalcitrance for the Recovery of Transgenic Cowpea: Implications of Selection Strategies. Journ. Plant Growth Regul., 32:148-158 DOI 10.1007/s00344012-9284-6 research through biotechnology research fund. The PhD Fellowship awarded to Lawan Abdu Sani by Bayero University, Kano, Nigeria is also acknowledged.

Bakshi, S., Sahoo, B., Roy, N. K., Mishra, S., Panda, S. K., Sahoo, L. (2012).Successfulrecovery of transgenic cowpea (Vigna unguiculata) using the 6-phosphomannose isomerase gene as the selectable marker. Plant Cell Rep., 31:1093-1103.DOI 10.1007/s00299-012-1230-3.

Brar, M. S., Al-Khayri, J. M., Morelock, T. E., Anderson, E. J. (1999).Genotypic response of cowpea (Vigna unguiculata L.) to in vitro regeneration from cotyledon explants. In Vitro Cell. Dev. Biol. Plant, 35:812.DOI:10.1007/s11627-999-0002-4.

Choudhary, K., Singh, M., Rathore, M. S., Shekhawat, N. S. (2009). Somatic embryogenesis and in vitro plant regeneration in moth bean [Vigna aconitifolia (Jacq.) Marechal]: a recalcitrant grain legume Plant Biotechnol. Rep., 3:205-211 DOI 10.1007/s11816-009-0093-8.

Citadin, C. T., Cruz, A. R. R. and Aragao, F. J. L. (2013).Development of transgenic imazapyr-tolerant cowpea (Vigna unguiculata). Plant Cell Rep., 32:537-543 doi:10.1007/s00299-013-1385-6 
Cruz, A. R. R. and Aragao F. J. L. (2013). RNAibased enhanced resistance to Cowpea severe mosaic virus and Cowpea aphidborne mosaic virus in transgenic cowpea. Plant Pathology,63(4)831-837, DOI: $10.1111 /$ ppa. 12178

Food and Agriculture Organization, (2012). The second report on the state of the world's plant genetic resources for food and agriculture - http/www.fao.org

Gamborg, O., Miller, R., Ojima, K. (1968). Nutrient requirements of suspension cultures of soybean root cells. Exp. Cell Res., 50:151-158.

Gurel, S., Baloglu, M. C., Gurel, E., Oktem, H. A., Yucel, M. (2011) A two stage pretreatment of seedlings improves adventitious shoot regeneration in sugar beet (Beta vulgaris L.). Plant Cell Tiss Organ Cult., 106(2):261-268

Kucharska, D. and Orlikowska, T. (2009) Enhancement of in vitroorganogenetic capacity of rose by preculture of donor shoots on the medium with thidiazuron. ActaPhysiol Plant 31:495-500

Mamman, T., Qian, L., Yanxia, Z. andHuanxiu, L. (2013). Effect of 6-BA on the Plant Regeneration via Organogenesis from Cotyledonary Node of Cowpea (Vigna unguiculataL. Walp).Journal of Agricultural Science, 5(5):2013, DOI:10.5539/jas.v5n5pl.

Mao, J. Q., Zaidi, M. A., Arnason, J. T. andAltosaar, I. (2006).In vitro regeneration of Vigna unguiculata(L.)Walp. cv. Blackcyc cowpea via shoot organogenesis. Plant Cell Tiss. Org. Cult. 87:121-125. DOI: 10.1007/s11240-006-9145-8.

Murashige, T. and Skoog, F. (1962).A revised medium for rapid growth and bioassay with tobacco tissue cultures.Physiol Plant.15:473-497.

Muthukumar, B., Mariamma, M., Gnanam,
A. (1996). Regeneration of plants from primary leaves of cowpea. Plant Cell Tiss. Org. Cult., 42:153-155. DOI:10.1007/BF00034232.

Nielson, S. S., Brandt, W. E. and Singh, B. B. (1993). Genetic variability for nutritional composition and cooking time of improved cowpea lines.Crop Sci. 33: 469472.

Pellegrineschi, A. (1997). In vitro plant regeneration via organogenesis of cowpea (Vigna unguiculata L.).Plant Cell Rep., 17:89-95. DOI:10.1007/s002990050358.

Popelka, J. C., Gollasch, S., Moore, A., Molvig, L. and Higgins, T. J. V. (2006). Genetic transformation of cowpea (Vignaunguiculata L.) and stable transmission of the transgenes to progeny.Plant Cell Rep; 25:304-12. doi:10.1007/s00299-005-0053-x.

Raji, A. A. J., Oriero, E., Odeseye, B., Odunlami, T. andlngelbrecht, I. L. (2008).Plant regeneration and Agrobacterium-mediated transformation of African cowpea [Vigna unguiculata (L.)Walp] genotypes using embryonic axis explants. Journal of Food, Agriculture \& Environment 6 (3 and 4), 350 - 356.

Raveendar, S., Premkumar, A., Sasikumar, S., Ignacimuthu, S. andAgastian, P. (2009).Development of a rapid, highly efficient system of organogenesis in cowpea (Vigna unguiculata (L.).Walp).S. Afr. J. Bot., 75:17-21.

Sani, L. A., Usman, I. S., Ishiyaku, M. F and Bugaje, S. M. (2015). Towards Efficient In vitro Regeneration of Cowpea (Vigna unguiculata L. Walp): A Review. British Biotechnology Journal,7(4): 174-182.

Singh, B. B., Ehlers, J. D., Sharma, B. and Freire-Filho, F. R. (2000). Recent progress in cowpea breeding. In: Proceedings of World Cowpea Conference III, 4-7 September 2000. IITA, Ibadan, Nigeria, pp. 22-40. 